\title{
Medical economic vulnerability: a next step in expanding the farm resilience scholarship
}

\author{
Florence A. Becot ${ }^{1}$ (D) . Shoshanah M. Inwood ${ }^{2}$
}

Accepted: 3 February 2022 / Published online: 16 February 2022

(c) The Author(s) 2022

\begin{abstract}
In recent years, the long-standing questions of why, how, and which farm families continue farming in the face of ongoing changes have increasingly been studied through the resilience lens. While this body of work is providing updated and novel insights, two limitations, a focus on macro-level challenges faced by the farm operation and a mismatch between the scale of challenges and resilience measures, likely limit our understanding of the factors at play. We use the example of medical economic vulnerability, a micro-level challenge traditionally confined to the household sphere of the agri-family system, as a way to call attention to these limitations. Focusing on United States (U.S.) farm households, we assess: (1) To what extent are they experiencing medical economic vulnerability when using objective and subjective outcome measures? (2) Which demographic and farm characteristics are associated with experiencing medical economic vulnerability? (3) What is the association between institutional arrangements and medical economic vulnerability? Our analysis of over 900 surveys coupled with a conceptual framework merging complementary insights from three bodies of literature revealed seemingly large differences in the prevalence of medical economic vulnerability across the objective and subjective measures with the subjective measure indicating a general sentiment of medical economic vulnerability in a majority of respondents. Conversely, limited variations were noted in who experiences medical vulnerability on the basis of demographic and farm characteristics, with stronger associations being connected to the households' health insurance arrangements. We conclude with three implications of our findings for the farm resilience literature.
\end{abstract}

Keywords Farm resilience $\cdot$ Household level difficulties $\cdot$ Health insurance $\cdot$ Medical economic vulnerability $\cdot$ Objective vs. subjective measures $\cdot$ Agri-family system

$\begin{array}{ll}\text { Abbreviations } \\ \text { ACA } & \text { Patient Protection and Affordable Care Act } \\ \text { ARMS } & \text { Agricultural Resource Management Survey } \\ \text { COVID-19 } & \text { Coronavirus Disease 2019 } \\ \text { EFA } & \text { Exploratory factor analysis } \\ \text { FSA } & \text { Flexible spending accounts } \\ \text { HSA } & \text { Health savings account } \\ \text { MICE } & \text { Multiple imputation by chained equation } \\ \text { U.S. } & \text { United States }\end{array}$

Florence A. Becot

becot.florence@marshfieldresearch.org

Shoshanah M. Inwood

inwood.2@osu.edu

1 National Farm Medicine Center, Marshfield Clinic Research Institute, 1000 N Oak Ave, Marshfield, WI 54449, USA

2 School of Environment and Natural Resources, The Ohio State University, 132 Williams Hall, 1680 Madison Avenue, Wooster, OH 44691, USA

$\begin{array}{ll}\text { USDA } & \text { United States Department of Agriculture } \\ \text { VIF } & \text { Variance inflation factor }\end{array}$

\section{Introduction}

In life and agriculture, the one certainty is change. The inherent instability of the agricultural sector associated with biophysical processes and the influence of social, political, and economic forces on the sector have long led rural social scientists to study why, how, and which farm families stay on the land in the face of unrelenting change. Depending on geographical context and time-period, these questions have historically been examined through several strands of literature, most notably the "agrarian question" and "farm persistence" (e.g. Akram-Lodhi and Kay 2010a, b; Buttel 2001; Reinhardt and Barlett 1989). In recent years, these questions have increasingly been studied through the "farm resilience" lens (e.g. Darnhofer et al. 2016; Kangogo et al. 
2020; Sinclair et al. 2014). Setting aside some of the theoretical scrutiny on the definition and usefulness of the resilience concept (for these debates see for example Calo 2020; Darnhofer et al. 2010; Hall and Lamont 2013), the farm resilience literature is broadly concerned with farm systems' adaptation and transformation to maintain their function in the long-term in response to vulnerabilities in the shortand medium-term. In turn, vulnerabilities, also commonly referred to as challenges, are the specific perturbations that negatively impact the functioning of farm systems (Darnhofer et al. 2016; Meuwissen et al. 2019; Urruty et al. 2016).

Several drivers are likely spurring the growth of the farm resilience literature. The interdisciplinary grounding of the concept considers the dynamic interdependences of natural and social systems (Darnhofer et al. 2016) and reflects the growing trend in transdisciplinary team science. This approach lies in contrast to the social systems focus of the farm family literature in the late twentieth century. The growth of the farm resilience literature may also be explained by the omnipresence of the concept of "resilience" itself in governmental and non-governmental organizations discourses (e.g. USDA 2021; World Bank n.d.). However, in our review of the farm resilience literature focused on Western industrialized countries, we identified two limitations that may hinder a holistic understanding of: (a) the range and frequency of challenges that farm families face, and (b) the range of factors that shape farm family resilience. As this body of work continues to evolve, it is helpful to reflect on how these knowledge gaps likely constrict our understanding of the types of interventions that might best support the people in the farm sector and their ability to weather crises.

The first limitation is connected to a doubly narrow prevailing conceptualization of what constitutes stresses and shocks (hereafter described as challenges). On one hand, farm resilience scholars tend to focus on macro-level challenges which impact many farms at once within a geographic area may it be at the sub-national, national, or international scale. These include major weather events (Javadinejad et al. 2020), political and economic structural shifts such as agricultural deregulation (Forney and Stock 2014), and public health crises such as Coronavirus Disease 2019 (COVID-19; Darnhofer 2020). Micro-level challenges that may only impact a few farms at once within a geographical area, such as a barn fire or a wild animal attack of livestock, have received much less attention. Yet, similar to macro-level challenges, these micro-level challenges have short-term impacts on the farm operation due to the loss and redirection of resources (i.e. money and labor) with potential long-term consequences on farm resilience. One the other hand, farm resilience scholars largely focus on challenges that impact the farm operation. Seldom do they consider those faced by farm households such as a major illness, divorce, or loss of off-farm employment (Komarek et al. 2020; Popp and Nowack 2020). The lack of attention to these household-level challenges and how they may affect farm resilience is surprising given the farm resilience studies that have documented the key buffering functions played by farm households within the multi-scalar farm system, as the deep interconnections and exchange of resources between the farm household and the operation help to absorb shocks to the enterprise (Doeksen and Symes 2015; Meuwissen et al. 2019).

The second limitation is connected to the contradiction and mismatch in the scale at which challenges and resilience indicators are measured. While much of the farm resilience research focuses on macro-level challenges, studies tend to emphasize the micro-level variables associated with vulnerability and resilience, such as farmers socio-demographic characteristics, farm operation characteristics, farmers' actions and pre-disposition, and their adaptation strategies (Darnhofer et al. 2016; Daugstad 2019; Diserens et al. 2018; Greenhill et al. 2009; Kangogo et al. 2020). As scholars critiquing the resilience lens have argued (speaking about the application to agriculture and other topics), the de facto interpretation of this micro-level focus is to interpret resilience through an individual's deficits (Calo 2020; Cote and Nightingale 2012; Hall and Lamont 2013; Joseph 2013). Often missing are factors outside of farmer's control that affect their decision-making and shape farm resilience. Meso and macro-level variables such as community infrastructures, rural labor markets, or government programs have received limited attention even though these institutional arrangements play an important role in amplifying or mitigating the effects of challenges that farm families face (Greenhill et al. 2009; Popp and Nowack 2020; Thorsøe et al. 2020). Without considering how meso and macro-level factors shape farm resilience, we limit our ability to assess the interplay and interactions between micro, meso, and macro level factors, and we constrict our ability to understand how power differentials across these different scales affect short- and long-term farm resilience.

In this article, we use the example of medical economic vulnerability among United States (U.S.) farm families to speak to the two limitations of the farm resilience literature. Our article also connects to recent calls to expand the range of challenges studied (Komarek et al. 2020; Meuwissen et al. 2019; Popp and Nowack 2020) and to expand our understanding of the factors that shape these challenges including through the assessment of system's features that can enable or constrain a farmers' ability to adapt (Darnhofer 2021). Medical economic vulnerability (i.e., experiencing economic and social difficulties due to health expenses) is illustrative of a micro-level challenge that is generally confined to the household and one for which institutional arrangements in the form of health insurance likely play an important role in softening the blow of a medical crisis. Our 
three research questions are: (1) To what extent are U.S. farm households experiencing medical economic vulnerability when using objective and subjective measures of vulnerability? (2) Which demographic and farm characteristics are associated with experiencing medical economic vulnerability? (3) What is the association between institutional arrangements, namely health insurance, and medical economic vulnerability? We draw on a primary data set of over 900 surveyed farm households from 10 states along with secondary data on health insurance and labor market environments. Our conceptual framework is based on three distinct bodies of literature which brought together speak to the range of factors within the multi-scalar agri-family system that shape medical economic vulnerability. Furthermore, our comparison of objective and subjective outcome measures provide a multi-dimensional perspective into the frequency and factors that shape farm families' vulnerability.

Our presentation of the empirical case is preceded by a literature review on health challenges in agriculture and interactions with the farm operation in addition to providing a description of our medical economic vulnerability conceptual framework.

\section{Literature review: health challenges and medical economic vulnerability in agriculture}

Health challenges are common in agriculture as it ranks as one of the most dangerous occupations globally due to the risky nature of the worksite (Donham and Thelin 2016; International Labor Organization 2014; Shortall et al. 2019). The physical nature of the work also takes a toll on the body with the proportion of physical limitations increasing with age (Peters et al. 2008; Reed 2008). Besides impacting farmers' quality of life, these health aliments, whether they are temporary or permanent, negatively impact the farm business. Health difficulties may limit the tasks farmers can do, which can lead to a decrease in productivity and early farm exit (Chang et al. 2011; Inwood et al. 2018). Depending on the availability and strength of the social safety net, healthrelated expenses can also represent a source of economic pressure for the farm as health-related expenses can divert resources away from the farm operation while loss of work time and cost of replacement labor can impact farm income (Dulitz and Schrader 2013; Inwood 2015; Lottero et al. 2007).

Research from low and medium income countries highlights the importance of considering health challenges along with the macro-level structural challenges that impact the farm operation (Alam and Mahal 2014; Bonfrer and Gustafsson-Wright 2017). This body of work has found that accidents and illnesses can be more frequent than farm-level challenges such as crop failures and major storms and they can affect anyone no matter the scale of operation, commodities produced, climatic conditions, or social policy environments. Furthermore, health insurance plays a crucial role in supporting the farm household and operation by removing, or at least softening, the blow of health related-expenses.

Overall, previous research on medical economic vulnerability among farmers in Western industrialized countries comes from the U.S. and largely pre-dates the 2010 Patient Protection and Affordable Care Act $\left(\mathrm{ACA}^{1}\right)$. This points to a gap in our understanding of the ways in which health challenges may impact farm resilience. U.S. studies highlight the problem of underinsurance among farmers (i.e., a situation when health insurance coverage does not offer adequate financial protection). A 2007 survey of 2017 Midwest farmers found that while over $90 \%$ of farmers had health insurance coverage, $18 \%$ had a medical debt (Pryor et al. 2009). Meanwhile, a 2012 survey of 205 South Dakota farmers found that $91 \%$ had health insurance yet $62 \%$ reported making sacrifices due to health expenses (Dulitz and Schrader 2013). Though these challenges might not be as acute in other Western industrialized countries as they are in the U.S. due to stronger social safety nets, there is international evidence that some farmers are experiencing difficulties accessing and paying for health care. For example, French farmers reported difficulties associated with low reimbursement rates for some health services while Swiss farmers faced challenges associated with high health insurance costs and out-of-pocket expenses (Chappuis et al. 2015; Droz et al. 2014; Roche 2016).

The limited consideration of medical economic vulnerability among farm households and the ways in which health challenges can affect the farm operation and ultimately farm resilience may be partially attributed to difficulties accessing data on farmers' health and health insurance data as previously noted (Chang et al. 2011; Droz et al. 2014). The U.S. Department of Agriculture (USDA) collects data on source of health insurance coverage and health care expenditure. Yet the lack of data on health status and lived experiences along with limited demographic data have largely limited research to interactions between health insurance coverage with labor allocations and off-farm employment (e.g., Ahearn et al. 2013; Mishra et al. 2018). In this study, we leverage our access to a primary dataset of U.S. farm families to which we add secondary data on health insurance and labor markets to assess the prevalence and factors associated with medical economic vulnerability. ${ }^{2}$

\footnotetext{
${ }^{1}$ For a review of how the ACA re-shaped the health insurance landscape and how it was expected to impact the farm sector see Ahearn et al. (2015) and Inwood (2017).

2 At the time of our study in the early years of implementation of the ACA, a federal mandate required all individuals to either have health
} 


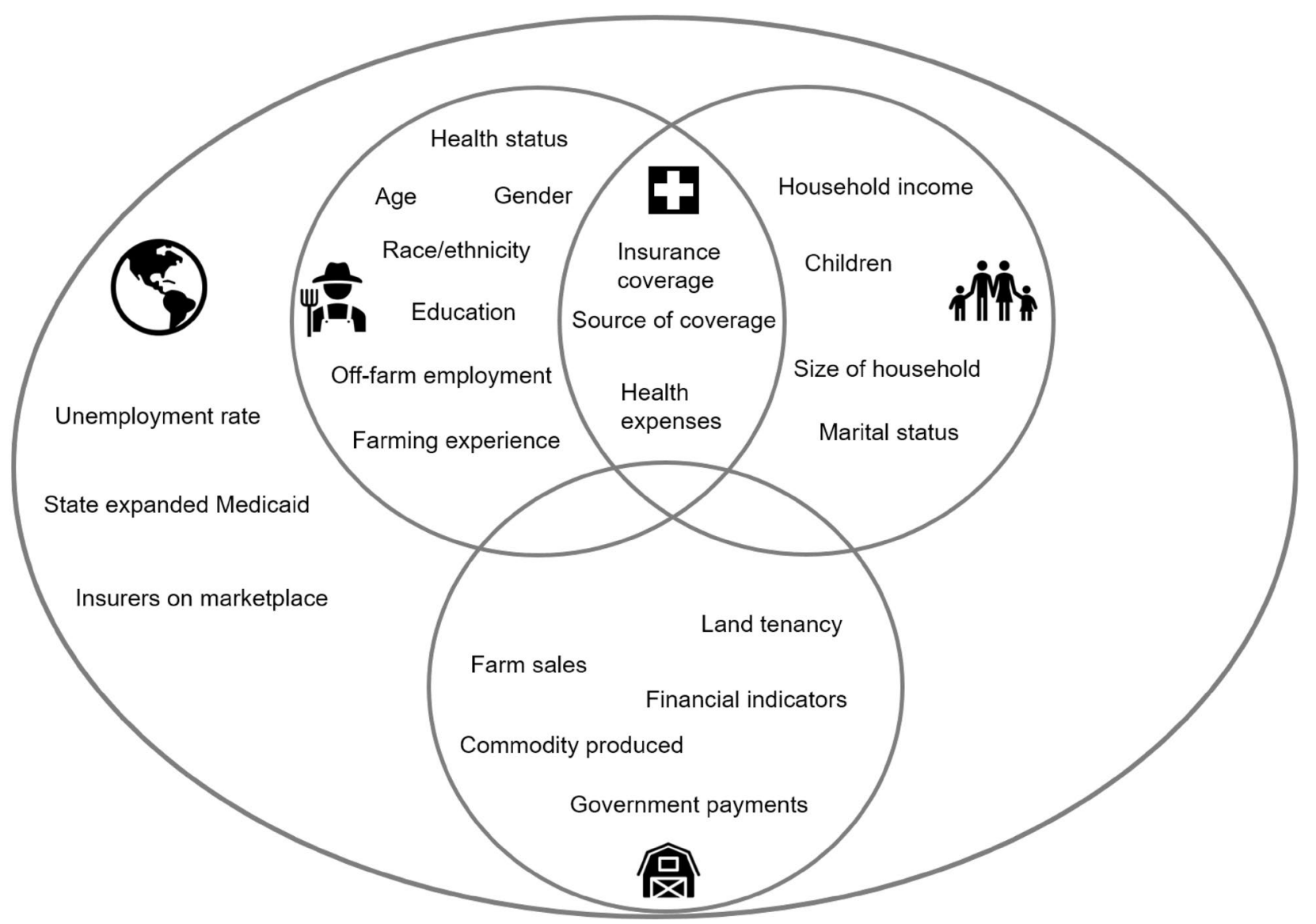

Fig. 1 Conceptual framework of farm families' medical economic vulnerability. Note conceptual framework variables are from the merging of three bodies of literature: (1) medical economic vulner-

\section{Conceptual framework}

Given the limited number of studies examining farm families' medical economic vulnerability, we developed our conceptual framework by merging three distinct, but complementary, bodies of literature: (1) medical economic vulnerability in the U.S., (2) farm economic stress and bankruptcy literature (largely based on the U.S. literature), and (3) farm family literature, including farm resilience. First, we identified and summarized the independent variables

Footnote 2 (continued)

insurance or pay a tax penalty. This mandate ended in 2019 but five states have since then instituted a state-level mandate. Farmers can obtain health insurance from a range of sources including from the federal government for aged-based universal coverage starting at 65 or for individuals with a disability, state-level government for meansbased coverage, through their off-farm employer, and through the purchase of a plan from a private insurer. Readers not familiar with the U.S. health insurance system can refer to Field (2017) and Rice et al. (2013) for a general overview. ability in the U.S., (2) farm economic stress and bankruptcy literature (largely based on the U.S. literature), and (3) farm family literature, including farm resilience

associated with medical and farm economic vulnerability. Then, we drew on the farm family literature, in particular its description of the complex-agri family system, as a backdrop to organize the variables from the medical and farm economic vulnerability bodies of literature (Fig. 1).

By showing the individual ( and farm operation (回) as overlapping spheres, our conceptual framework underscores the interactions between these micro-level spheres within the agro-family system (Bennett and Kohl 1982; Doeksen and Symes 2015; Komarek et al. 2020; Meuwissen et al. 2019; Popp and Nowack 2020; Reinhardt and Barlett 1989). By showing the micro-level spheres embedded within the larger environments connected to meso- and macro-level spheres ( $($ ), our framework underscores the ways in which larger environments intersect with farm families' choices and access to resources (Bennett and Kohl 1982; Meuwissen et al. 2019; Popp and Nowack 2020; Smithers and Johnson 2004; Thorsøe et al. 2020). We inserted the variables associated with health insurance arrangements (F) at the intersection of the individual and farm household spheres since 
eligibility criteria and cost of coverage are heavily shaped by the characteristics of these two spheres. As with most graphical representations, our conceptual framework is simplified to enhance readability and streamline operationalization. This simplification includes the merging of meso- and macro-level spheres into one and placing certain factors into one sphere even though they could have been placed in multiple spheres.

While this conceptual framework was developed to study farm families' medical economic vulnerability, our framework also speaks to the limitations of the farm resilience literature highlighted in our introduction. By speaking to micro-, meso-, and macro-level variables within the agrifamily system, our framework provides an example of how multi-scalar factors can be better integrated into farm resilience research. The consideration of variables across scale provides an opportunity to further our understanding of the interplay between individual variables and systems' features. We now summarize the factors associated with medical and farm economic vulnerability related to the components of our conceptual framework.

\section{Health insurance arrangements}

The U.S. medical economic vulnerability literature not only points to the importance of having health insurance but also to the type of coverage. Medical economic vulnerability is more likely to occur when households do not have health insurance, have experienced a gap in coverage, and have high out-of-pocket and deductible expenses (Banegas et al. 2016; Baughman et al. 2015; Hamel et al. 2016; Himmelstein et al. 2009; Pryor et al. 2008, 2009). The source of coverage associated with vulnerability is not consistent across studies. Hamel et al. (2016) and Pryor et al. (2008) found a greater probability of medical economic vulnerability for those covered through a private plan with high deductibles or purchased on the individual marketplace, while Banegas et al. (2016) found a greater probability among those who were insured through a public plan.

\section{Individual and household characteristics}

The medical economic vulnerability and farm economic stress and bankruptcy bodies of literature indicate a number of individual and household level characteristics associated with economic vulnerability. Individuals more likely to be economically vulnerable have poorer health status, have a pre-existing or chronic health condition, are female-headed households and/or operated farms, are African American, have children, have larger households, have lower educational attainment, have lower household income, and are beginning farmers ( $<10$ years of experience) (Banegas et al. 2016; Baughman et al. 2015; D'Antoni et al. 2009; Katchova and Dinterman 2018; Nadolnyak et al. 2019; Pryor et al. 2009; Wiltshire et al. 2016).

Findings on the association between income source and age are contradictory. In a study of medical economic vulnerability, Pryor et al. (2008) found that full-time farming households (i.e. those without off-farm employment) were more vulnerable than those farming part-time. Looking at the financial stress of beginning farmers, D'Antoni et al. (2009) found that financial hardship decreased as the share of income from farming increased. While some studies found that younger households are more likely to be vulnerable, others did not find age-related associations (Baughman et al. 2015; D'Antoni et al. 2009; Hamel et al. 2016; Himmelstein et al. 2009; Katchova and Dinterman 2018; Pryor et al. 2008, 2009). This discrepancy in findings around age reinforces the need to consider household composition and life course variations while also considering health insurance arrangements since in the U.S., access to some public plans and the ability to be covered by a parents' insurance have an age criterion. While not mentioned in the farm economic stress and bankruptcy studies, the broader farm family literature has also found that farming background (i.e., whether someone grew up on a farm) shapes access to financial resources and social networks with multi-generational farmers having greater access to resources than first-generation farmers (Carolan 2018; Clark et al. 2010; Inwood et al. 2013).

\section{Farm operation characteristics}

Farm operations that are more likely to be economically vulnerable include small- and large-scale operations as their sales are either low or their financial leverage is high (Bryant and Maisashvili 2017; D'Antoni et al. 2009; Franks 1998; Katchova and Dinterman 2018). However, there are no clear patterns in the associations between economic vulnerability for farm income, commodities produced, land tenancy, and government payments (D'Antoni et al. 2009; Franks 1998; Katchova and Dinterman 2018; Nadolnyak et al. 2019; Shepard and Collins 1982). This lack of pattern might be due to differences across studies reflecting their variations in geographical areas, outcome measures, or use of aggregate vs. farm operation level data.

\section{Macro-level environments}

The last set of variables is connected to macro-level environments. According to the farm economic vulnerability literature, greater vulnerability is associated with higher 
unemployment rates at the county level due to the importance of off-farm employment for household income (Dinterman et al. 2018; Nadolnyak et al. 2019). To our knowledge, medical economic vulnerability scholars have not considered the role played by the county- and state-level health insurance environments. However, research assessing the impact of the ACA on health insurance coverage and cost has found increased coverage in states that have expanded Medicaid and relationships between number of insurance plans offered on the marketplace and cost of premiums (Antonisse et al. 2019; Burke et al. 2014; Frank and McGuire 2017; Mazurenko et al. 2018).

\section{Data and methods}

\section{Research design and data collection}

We use a mix of primary and secondary data to answer our research questions. Primary data on health insurance arrangements, individual and household characteristics and farm operation characteristics are from a national survey to understand how health insurance impacts farms and ranches. The instrument was designed using several bodies of literature (health insurance and health care access with a focus on rural areas and the farm population, health literacy, and farm business development) and insights from key informant interviews with University Extension personnel, tax preparers, farm organizations, and state department of agriculture staff. The secondary data examining macro-level county and state level health insurance and labor markets are from publicly available data sets (Henry Kaiser Family Foundation 2019; Robert Wood Johnson Foundation n.d.; USBLS 2016).

We used the tailored design method for mail and online surveys to deploy the survey (Dillman et al. 2014). The surveyed population was farm households in 10 states (California, Kentucky, Massachusetts, Michigan, Mississippi, Nebraska, Pennsylvania, Utah, Vermont, and Washington State) which were selected using two criteria. First, we selected two states in each of the four USDA regions (Northeast, North Central, South, and West) to account for regional and production variations. Then in each region, we selected a state that had expanded Medicaid and a state that had not (except in the Northeast region) to account for health insurance policy variations. We sent introductory letters, multiple mailing and emailing of the survey instruments, and reminder letters February-April 2017 to a purchased list of 10,165 randomly selected farm households. The letter asked that the household member with the most knowledge about health insurance fill out the survey. Paper surveys were entered manually then merged with the online survey responses. We conducted quality control during the data entry and merging processes including checking for accurate data entry and duplicate responses. We received 1292 completed surveys. After removing bad addresses and blanked surveys, the response rate was 13\%. Despite the low response rate, our sample of 1292 respondents is above the 384 sample-size threshold for $95-5$ confidence level-margin of error since there are 536,000 primary operators living in the 10 study states (U.S. Department of Agriculture 2017). We removed responses from 113 hobby farms (sales under $\$ 10,000$ ) from our dataset to focus on farmers that are most likely to be commercially-oriented. For further discussion on the research design, see Inwood et al. (2018). The research protocol was determined to be exempt from review by the University of Vermont Institutional Review Board.

\section{Measures and recoding}

The variables used for analysis along with the descriptive statistics are listed in Table 1, and the independent variables are organized under the headers of our conceptual framework (Fig. 1).

\section{Outcome variables}

We used objective and subjective measures to assess medical economic vulnerability. Our rationale for using two types of measures is justified by the bodies of literature that underpin our conceptual model. The farm resilience and farm economic stress bodies of literature have been critiqued for their overreliance on objective measures which prevent the development of a holistic understanding that incorporates farmers' perceptions, goals, and lived realities (see Darnhofer et al. 2016; Kuhmonen 2020; Meuwissen et al. 2019; Perrin et al. 2020 for critiques of the farm resilience literature and Gillespie and Johnson 2010; Rissing 2019 for critiques of the agricultural economics literature). The medical economic vulnerability literature reinforces the importance of incorporating subjective measures because the perception of economic vulnerability has been associated with poor mental and physical health outcomes (Richardson et al. 2013; Sweet et al. 2013).

Our objective measure is "having a medical debt over $\$ 1,000 "$ "; the $\$ 1000$ debt threshold was selected based on previous medical bankruptcy research (Himmelstein et al. 2009). Collected as a dummy variable, this response did not require recoding. Our corresponding subjective measure is based on the question "Given your current financial and health insurance situation, how confident are you that you could pay the medical costs, without going into debt, if you had a major illness or injury such as heart attack, cancer, or loss of limb?" This response was initially measured using a five-point Likert scale and collapsed to three categories to ensure we had at least five observations for analysis in the dependent/independent variable cross-tabulations. Since our 
Table 1 Study variables and descriptive statistics $(n=1179)$

Outcome variables: measures of medical economic vulnerability

Medical debt over $\$ 1000^{\mathrm{a}}$ (objective measure)

Confidence can pay for major health expenses without going into debt ${ }^{\mathrm{b}}$ (subjective measure)

Not at all or slightly confident

Neutral

Moderately or very confident

Independent variables: health insurance arrangements (F)

Had health insurance for all household members all year

All household has same plan

Source of health insurance

Off-farm employment

Direct purchase of private plan

Age-based public health insurance

21.3

Means-based public health insurance

Farm Bureau or Farmers' Union

Monthly insurance premium in 2016

Health insurance deductible

None

$\$ 1$ to $\$ 1999$

31.0

$\$ 2000$ to $\$ 5000$

More than $\$ 5000$

Out-of-pocket expenses

Up to $\$ 999$

$\$ 1000$ to $\$ 2999$

$\$ 3000$ to $\$ 4999$

$\$ 5000$ and over

Health savings account

Flexible spending account

Independent variables: farm individual (

Pre-existing or chronic condition

Age of respondent

Children under 18

White, non-Hispanic/Latino

Education

High school or less $\quad 37.3$

$\begin{array}{ll}\text { Some college } & 20.8\end{array}$

Bachelor's degree and higher $\quad 42.9$

Off-farm job

Beginning farmer

Independent variables: farm operation (鄗)

Farm sales

Small

Large

Multi-generational farm

Commodity produced 
Table 1 (continued)

\begin{tabular}{|c|c|c|}
\hline & Percent & Mean (standard error) \\
\hline Livestock & 37.9 & \\
\hline Dairy & 20.0 & \\
\hline Fruits and vegetables & 13.8 & \\
\hline \multicolumn{3}{|c|}{ Independent variables: health insurance and labor market $(6)$ environments } \\
\hline State expanded Medicaid & 56.8 & \\
\hline Number insurers on marketplace & & $6.8(3.3)$ \\
\hline Unemployment rate & & $4.6(2.0)$ \\
\hline
\end{tabular}

ordinal logistic model with survey responses on the threepoint scale failed the proportionality odds assumption test, we ultimately chose to recode this variable as a dummy variable (not confident vs. neutral or confident) for two reasons. First, while a multinomial logistic model is generally recommended when the proportionality odds assumption is not met in the ordinal logistic model, the interpretation of multinomial logistic models results is cumbersome. Second, by having dummy objective and subjective measures, we can more easily compare the results of our two models.

Similar to the limitations associated with the use of unidimensional variables in farm resilience and farm economic stress assessments, the use of two dummy variables to assess medical economic vulnerability is a limitation of our study design. In an attempt to address this limitation, we conducted an exploratory factor analysis (EFA) to create a composite measure for the subjective response using three survey questions. ${ }^{3}$ EFA results reached satisfactory thresholds but missing observations led to an important drop in the sample size in the multivariate analysis. Therefore, we elected to conduct our assessment using one subjective measure. Future work aimed at furthering the development of multidimensional measures of resilience and vulnerability is needed.

\section{Independent variables}

The independent variables speak to our conceptual framework. Starting with health insurance arrangements, measures include insurance coverage in the previous year, source of coverage, costs (i.e., premiums, deductible, and out-ofpocket expenses), and health savings tools [i.e., health

\footnotetext{
3 The three Likert-scale variables used in the EFA are as follows: (1) Health insurance meets needs, (2) Confidence that can afford the usual medical costs they currently have (assuming no emergency), (3) Confidence that can pay medical costs, without going into debt, if had a major illness or injury.
}

savings account (HAS) and flexible spending accounts (FSA)]. We collapsed the insurance coverage variable from three to two categories (all household members had insurance all the time in the previous year vs. household members had no coverage or partial coverage) to satisfy the five observations per cell requirement of our selected analysis. The health insurance deductible and out-of-pocket expenses variables were collapsed from seven to four categories. Because having a medical debt is likely associated with the degree of confidence in the ability to pay for major medical expenses without going into debt, we added the medical debt variable as an independent variable in the subjective measure model.

The farm individual variables include age, gender, race/ ethnicity, and educational attainment while household level variables include health status (i.e. household member has a pre-existing or chronic health condition), children under 18 , off-farm employment, and beginning farmer status. Since some of the demographic variables were collected only for the survey respondent, we are unsure of the racial/ethnic makeup of the entire farming household. We collapsed the race and ethnicity variables from seven to two categories (i.e., White, non-Hispanic/Latino vs. Farmer of Color) and educational attainment from five to three categories.

The farm operation variables include farming background (i.e., parent or other relatives ran the farm before respondent), commodity produced, and farm sales. We collapsed farm sales from eight to three categories using the USDA farm size categories based on farm sales (small, medium, and large). ${ }^{5}$ While previous farm economic stress studies have collected data on land tenancy, farm financial

\footnotetext{
${ }^{4}$ HSA and FSA accounts are savings accounts that provide tax advantages for eligible health expenses. Only those with a high deductible health plan are eligible for an HSA account while only those with an insurance group or employer plan are eligible for an FSA account.

5 USDA categories based on farm sales: hobby: less than $\$ 10,000$ (category was removed from our sample), small: between $\$ 10,000$
} 
indicators, and government payments, we did not collect these measures.

Last, publicly available data connected to health insurance and labor market environments for the study states were merged to the survey data using state and ZIP code as the merging variables. This included Medicaid expansion status (Henry Kaiser Family Foundation 2019), number of health insurance plans on the state and county market places (Robert Wood Johnson Foundation n.d.), and county-level unemployment rate (USBLS 2016).

A limitation to our study is that the survey instrument did not include independent variables that are associated with vulnerability in the medical economic vulnerability and farm economic stress literatures (i.e. household income, land tenancy, farm financial indicators, and government payments). To address the significance of household income as a factor, we assessed potential specification errors by running our preliminary multivariate analysis with and without a household income estimate from the USDA. ${ }^{6}$ Based on the model fit tests, coefficients, and standard errors, there were no noticeable differences between the models with and without the household income estimate. Furthermore, the linktest, a STATA function to test for additional predictors that are not statistically significant other than by chance, indicated no misspecification error in our models.

Another study limitation is our greater use of household's health insurance arrangements variables over health insurance environment variables. The U.S. health insurance system is a complex patchwork of options from the public, private, and/or non-profit sectors with an emphasis on consumers' choice (Rice et al. 2013). While some could argue that micro-level variables prevents us from assessing the role of institutional arrangements, scholars have pointed to the illusion of choice as health insurance choices are driven by a complex set of drivers largely outside of consumer's choices (Mulligan et al. 2019). As such, the specifics of households' health insurance are connected to institutional arrangements. For example, for households with coverage through off-farm

\footnotetext{
Footnote 5 (continued)

and $\$ 249,999$, medium: between $\$ 250,000$ and $\$ 499,999$, and large: $\$ 500,000$ and over.

6 To create a household income estimate to assess potential specification errors in the multivariate analysis, Daniel Prager, previously at the USDA, extracted farmer responses located in the 10 states from the 2016 ARMS dataset (except for 2 states where regional data were used). He then estimated a range of household income estimates for this sub-sample using a combination of five variables collected both in the ARMS survey and ours: (1) off-farm employment, (2) total farm sales $\geq \$ 250 \mathrm{~K}$, (3) educational attainment of at least some college, (4) primary operator is $\geq 65$ years of age, (5) beginning farmer status). We then merged this newly estimated household income in our dataset by matching the five variable combination.
}

employment, the employer chooses the coverage they offer which is determined by what private insurers in their area offer.

\section{Analytical strategy}

We first conducted bivariate analysis to assess the prevalence of medical economic vulnerability using the objective and subjective measures as outcomes variables. We then conducted logistic regression analysis to assess the factors associated with medical economic vulnerability (model 1: objective measure; model 2: subjective measure; model 3: subjective measure with the addition medical debt as an independent variable). We clustered the standard error at the state-level in the multivariate models to account for the multilevel conceptual framework. ${ }^{7}$ We used a nested modelling approach in the subjective outcome model to test the importance of the debt variables in the perception of medical economic vulnerability. The likelihood ratio test comparing models 2 and 3 indicates that the model fit is improved when the medical debt variable is added in model $3(\mathrm{p}=0.042)$. Last, because health care needs vary across the life course and eligibility criteria for universal public insurance coverage is age-based (i.e., age 65), we first added age as a quadratic term in the models to assess curvilinearity in the relationship between medical economic vulnerability and age. The significance levels for the age square term were above 0.05 in the three models indicating that the relationship between the dependent and independent variables is linear. Therefore, we did not include age as a quadratic term in the final models. Model diagnostics indicate that the three models have acceptable fit for the data based on the Hosmer-Lemshow test, there are no specification errors based on the linktest, no multicollinearity [mean variance inflation factor (VIF) was $\sim 1.52$ across the three models and maximum VIF value was 2.77], and there are no major influential observations based on Pearsons and deviance residuals.

To limit potentially biased estimators from missing observations, we conducted the bivariate and multivariate analysis on imputed datasets (He 2010; van Ginkel et al. 2020). Between 47 and 52\% of the observations did not have any missing values in the logistic models. The highest proportion of missing values was for the "health insurance premium' variable with $34 \%$ of observations missing while $6 \%$ of observations were missing the subjective outcome measure. We used the multiple imputation by chained

\footnotetext{
${ }_{7}$ Multilevel analysis can be indicated to parse out the effects of variables at various levels of analysis. We did not have the generally recommended number of clusters (at least 20) to conduct this type of analysis (Hox 2010).
} 
equation (MICE) approach, which accounts for categorical and dummy variables, with 35 iterations (Royston and White 2011; UCLA n.d.; White et al. 2011). All model variables were included in the imputation model but we did not impute the outcome variables values (Allison 2012; UCLA n.d.). We polled the imputed datasets for analysis using the Rubin's combination rule (Carlin et al. 2008). Our imputed datasets included 1009 and 993 observations, respectively, for the objective and subjective measures models compared to 617 and 616, respectively, for the unimputed analytical datasets. We conducted the imputation and data analysis in STATA IC (version 16) using the "mi" suite of commands.

The model F-tests on the imputed data indicate that in the three models, at least one of the independent variables is different from 0 meaning that the models are better fit than those with no predictors (model $1: \mathrm{F}=48.81$, $\mathrm{p}=0.000$, adjusted $\mathrm{R}^{2}=7.7 \%$; model $2: \mathrm{F}=97.80, \mathrm{p}=0.000$, adjusted $\mathrm{R}^{2}=11.3 \%$; model $3: \mathrm{F}=90.43, \mathrm{p}=0.000$, adjusted $\mathrm{R}^{2}=11.7 \%$ ). We assessed statistically significant differences across variables using $\chi^{2}$, ANOVA, and t-tests with the threshold level of significance set at $\mathrm{p} \leq 0.05$.

\section{Results}

\section{Characteristics of the sample}

The characteristics of the sample are available in Table 1 . Starting with the health insurance arrangement variables, 92.5\% of respondents reported that all household members were covered by health insurance all year, and $73.1 \%$ reported having one insurance plan for their household. The most frequent source of coverage was through off-farm employment (34.3\%) followed by a privately purchased plan (33.8\%), and age-based public health insurance (i.e., Medicare) (21.3\%). Respondents spent on average $\$ 750.8$ in monthly health insurance premiums in 2016 (standard deviation \$833.4), and over half of respondents had deductibles over $\$ 2000$ and out-of-pocket expenses over $\$ 3000$, respectively. Lastly, $22.8 \%$ of respondents had an HSA and $8.3 \%$ had an FSA.

Looking at farm individual and farm household characteristics, $59.5 \%$ of respondents reported that at least one household member had a pre-existing or chronic health condition and were on average 57.9 years old. The vast majority $(95.7 \%)$ of respondents were White, non-Hispanic/Latino, $38.7 \%$ were female, $42.9 \%$ had at least at bachelor's degree, $23.3 \%$ had children under $18,47.2 \%$ reported an off-farm job within the household, and $7.7 \%$ were beginning farmers.

Turning to farm operation characteristics, $39.7 \%$ of respondents operated small farms while $21.7 \%$ operated medium farms and $38.6 \%$ operated large farms. These farms produced grain $(53.4 \%)$, livestock $(37.9 \%)$, dairy $(20.0 \%)$, and fruits and vegetables (13.8\%). Over three-quarters of the operations were multi-generational farms.

Finally, when looking at the health and labor environment variables, $56.8 \%$ of respondents lived in a state that expanded Medicaid and there were on average 6.8 insurers on the state's insurance marketplace (standard error 3.3). The unemployment rate in the counties of residence was on average $4.6 \%$ (2.0 standard error).

\section{Prevalence of medical economic vulnerability among surveyed farm households}

Starting with the objective measure of economic vulnerability, one in five $(20.3 \%)$ surveyed farm households had a medical debt of at least $\$ 1000$ in 2016. The bivariate analysis reveals that few of the independent variables are statistically associated with the debt variable except for the health insurance arrangement variables and two of the individual and household variables (see Table 2 for variables with statistically significant differences; results for all variables are available upon request). Surveyed farm households who reported a medical debt in greater proportion included those who did not have insurance coverage for all members all year $(29.1 \%$ had a medical debt compared to $19.5 \%$ of surveyed households with full coverage), were covered by more than one insurance plan (26.9\% compared to $17.9 \%$ of households with one plan), had means-based public insurance (31.1\% compared to $19.0 \%$ of households without means-based public insurance), had higher deductibles (21.9\% of households with deductibles over $\$ 5000$ compared to $14.3 \%$ of households with no deductibles), had higher out-of-pocket expenses (28.7\% of households with expenses over $\$ 5000$ compared to $12.2 \%$ of households with expenses up to \$999), and had a pre-existing or chronic health condition (24.2\% compared to $14.6 \%$ ). Women respondents were also more likely to report that their household had a medical debt (24.0\% reported a debt compared to $17.9 \%$ of men respondents).

Turning to the subjective measure of medical economic vulnerability, over half (55.4\%) of surveyed farm households were concerned that they could not pay for the cost of a major illness or injury without going into debt. ${ }^{8}$ The bivariate analysis reveals that more independent variables are statistically associated with the subjective outcome measure than with the objective outcome measure. This

\footnotetext{
${ }^{8}$ We collapsed this variable into a dummy variable for the bivariate and multivariate analysis but $31.7 \%$ of respondents were moderately or very confident that they could pay for a major illness or injury without going into debt and $12.9 \%$ were neutral.
} 
Table 2 Farm households with medical debt and who are not confident that they could pay for cost of major illness or injury without going into debt (in \% unless otherwise noted)

\begin{tabular}{|c|c|c|c|c|}
\hline & \multicolumn{2}{|c|}{$\begin{array}{l}\text { Have medical debt } \\
(\mathrm{n}=1009)\end{array}$} & \multicolumn{2}{|c|}{ Not confident $(n=993)$} \\
\hline & Proportion & $\mathrm{p}$ & Proportion & $\mathrm{p}$ \\
\hline All farm households & 20.3 & - & 55.4 & - \\
\hline \multicolumn{5}{|l|}{ Health insurance arrangements () } \\
\hline Coverage for all household members all year & & 0.048 & & 0.001 \\
\hline Yes & 19.5 & & 54.0 & \\
\hline No & 29.1 & & 74.1 & \\
\hline All household members had same plan & & 0.002 & & n.s. \\
\hline Yes & 17.9 & & n.s. & \\
\hline No & 26.9 & & n.s. & \\
\hline Had medical debt over $\$ 1000$ & & n.a. & & 0.000 \\
\hline Yes & n.a. & & 66.6 & \\
\hline No & n.a. & & 52.6 & \\
\hline Off-farm employment & & n.s. & & 0.044 \\
\hline Yes & n.s. & & 51.4 & \\
\hline No & n.s. & & 57.9 & \\
\hline Direct purchase of private plan & & n.s. & & 0.042 \\
\hline Yes & n.s. & & 59.4 & \\
\hline No & n.s. & & 53.0 & \\
\hline Age-based public health insurance & & n.s. & & 0.000 \\
\hline Yes & n.s. & & 40.5 & \\
\hline No & n.s. & & 60.0 & \\
\hline \multirow[t]{3}{*}{ Means-based public health insurance } & & 0.005 & & n.s. \\
\hline & 31.1 & & n.s. & \\
\hline & 19.0 & & n.s. & \\
\hline Health insurance deductible & & 0.016 & & 0.000 \\
\hline No deductible & 14.3 & & 35.7 & \\
\hline$\$ 1$ to $\$ 1999$ & 15.9 & & 47.8 & \\
\hline$\$ 2000$ to $\$ 5000$ & 25.3 & & 60.2 & \\
\hline More than $\$ 5000$ & 21.9 & & 65.8 & \\
\hline Out-of-pocket expenses & & 0.000 & & 0.001 \\
\hline Up to $\$ 999$ & 12.2 & & 47.5 & \\
\hline$\$ 1000$ to $\$ 2999$ & 14.2 & & 49.7 & \\
\hline$\$ 3000$ to $\$ 4999$ & 24.0 & & 65.1 & \\
\hline$\$ 5000$ and over & 28.7 & & 59.3 & \\
\hline \multicolumn{5}{|l|}{ Farm individual ( } \\
\hline $\begin{array}{l}\text { Household member(s) with pre-existing or } \\
\text { chronic condition }\end{array}$ & 0.000 & & n.s. & \\
\hline Yes & 24.2 & & n.s. & \\
\hline No & 14.6 & & n.s. & \\
\hline Age (mean) & & & 55.4 & 0.000 \\
\hline At least one child under 18 & & n.s. & & 0.002 \\
\hline Yes & n.s. & & 63.8 & \\
\hline No & n.s. & & 52.5 & \\
\hline Female & & 0.021 & & 0.005 \\
\hline Yes & 24.0 & & 61.1 & \\
\hline No & 17.9 & & 51.9 & \\
\hline Education & & n.s. & & 0.001 \\
\hline HS or less & n.s. & & 59.3 & \\
\hline Some college & n.s. & & 63.5 & \\
\hline
\end{tabular}


Table 2 (continued)

\begin{tabular}{|c|c|c|c|c|}
\hline & \multicolumn{2}{|c|}{$\begin{array}{l}\text { Have medical debt } \\
(\mathrm{n}=1009)\end{array}$} & \multicolumn{2}{|c|}{ Not confident $(n=993)$} \\
\hline & Proportion & $\mathrm{p}$ & Proportion & $\mathrm{p}$ \\
\hline Bachelor's degree and higher & n.s. & & 48.0 & \\
\hline \multicolumn{5}{|l|}{ Farm operation (脸) } \\
\hline Multi-generational farmer & & n.s. & & 0.002 \\
\hline Yes & n.s. & & 58.2 & \\
\hline No & n.s. & & 46.5 & \\
\hline \multicolumn{5}{|l|}{ Commodity produced } \\
\hline Dairy & n.s. & n.s. & 63.8 & 0.007 \\
\hline Fruits and vegetables & n.s. & n.s. & 45.7 & 0.013 \\
\hline
\end{tabular}

n.a.. Not applicable, n.s.. not statistically significant

includes variables connected to health insurance arrangements. Surveyed farm households who reported not being confident in their ability to pay for major medical expenses in a greater proportion included those who did not have coverage for all members all year $(74.1 \%$ compared to $54.0 \%)$, had a medical debt over $\$ 1000$ (66.6\% compared to $52.6 \%$ of households without a debt), did not have insurance coverage through off-farm employment (57.9\% compared to $51.4 \%$ ), had coverage through a private plan (59.4\% compared to 53.0\%), did not have age-based public health insurance $(60.0 \%$ compared to $40.5 \%)$, had higher deductibles $(65.8 \%$ of households with deductibles over $\$ 5000$ compared to $35.7 \%$ of households with no deductibles), and had higher out-of-pocket expenses (59.3\% of households with expenses over $\$ 5000$ compared to $47.5 \%$ of those with expenses up to $\$ 999)$. Several of the individual, household, and farm operation variables were statistically significant. Farm households more likely to report that they were not confident were on average 55.4 years old (compared to an average age of 60.8 years for those who were confident or neutral), had children under 18 (63.8\% were not confident compared to $52.5 \%$ for households without children under 18), had lower levels of educational attainment $(59.3 \%$ for those with a high school degree or less compared to $48.0 \%$ for those with a bachelor's degree or more), were multi-generational farmers $(58.2 \%$ compared to $46.5 \%$ for first generation farmers), were dairy producers $(63.8 \%$ compared to $53.3 \%$ for farm operations that do not produce dairy), and did not grow fruits and vegetables (57.0\% compared to $45.7 \%$ of farm households grow fruits and vegetables). Last, women respondents were more likely to report not being confident (61.6\% compared to $51.9 \%$ for men respondents). We note that compared to the objective measures, there is no longer a statistically significant difference between households with pre-existing and chronic conditions compared to those without.

\section{Factors associated with medical economic vulnerability}

Our findings from the logistic regression models indicate that the patterns in statistical significance from the bivariate analysis hold in the multivariate analysis overall (Table 3). Starting with the factors associated with the objective measure of medical economic vulnerability (model 1), only health insurance arrangements and farm individual and household variables were statistically significant. Looking at the health insurance arrangement variables and controlling for the other independent variables, the odds of having a medical debt are $48 \%$ lower for households covered by the same insurance plan compared to households with more than one plan. In contrast, the odds of a farm household having a medical debt are 2.21 times higher for those with insurance deductibles between $\$ 2000$ and $\$ 5000$ compared to those with none, $74 \%$ higher for those with out-of-pocket expenses between $\$ 3000$ and $\$ 4999$, and 2.58 times higher for those with out-of-pocket expenses $\$ 5000$ and over compared to households with expenses up to $\$ 999,49 \%$ lower for households with HSA accounts, and $83 \%$ higher for those with an FSA account. Looking at individual and farm household variables, the odds of having a medical debt over $\$ 1000$ are 59\% higher for households with pre-existing or chronic conditions compared to those without and increase by $3 \%$ for every increase in age, are $63 \%$ higher for households with children under 18 , and are $47 \%$ higher for those with some college compared to those with a high school degree or less.

Examining the factors associated with the subjective measure (models 2 and 3 where debt is added as an independent variable in model 3), the significance of health insurance arrangement variables and individual and farm household characteristics shifted while variables connected to the farm operation became statistically significant. As discussed in the methods section, the addition of the debt variable improved model fit, and therefore, we focus our interpretation of the findings on model 3. Controlling for the 
Table 3 Logistic regression predicting the probability of farm households experiencing medical economic vulnerability

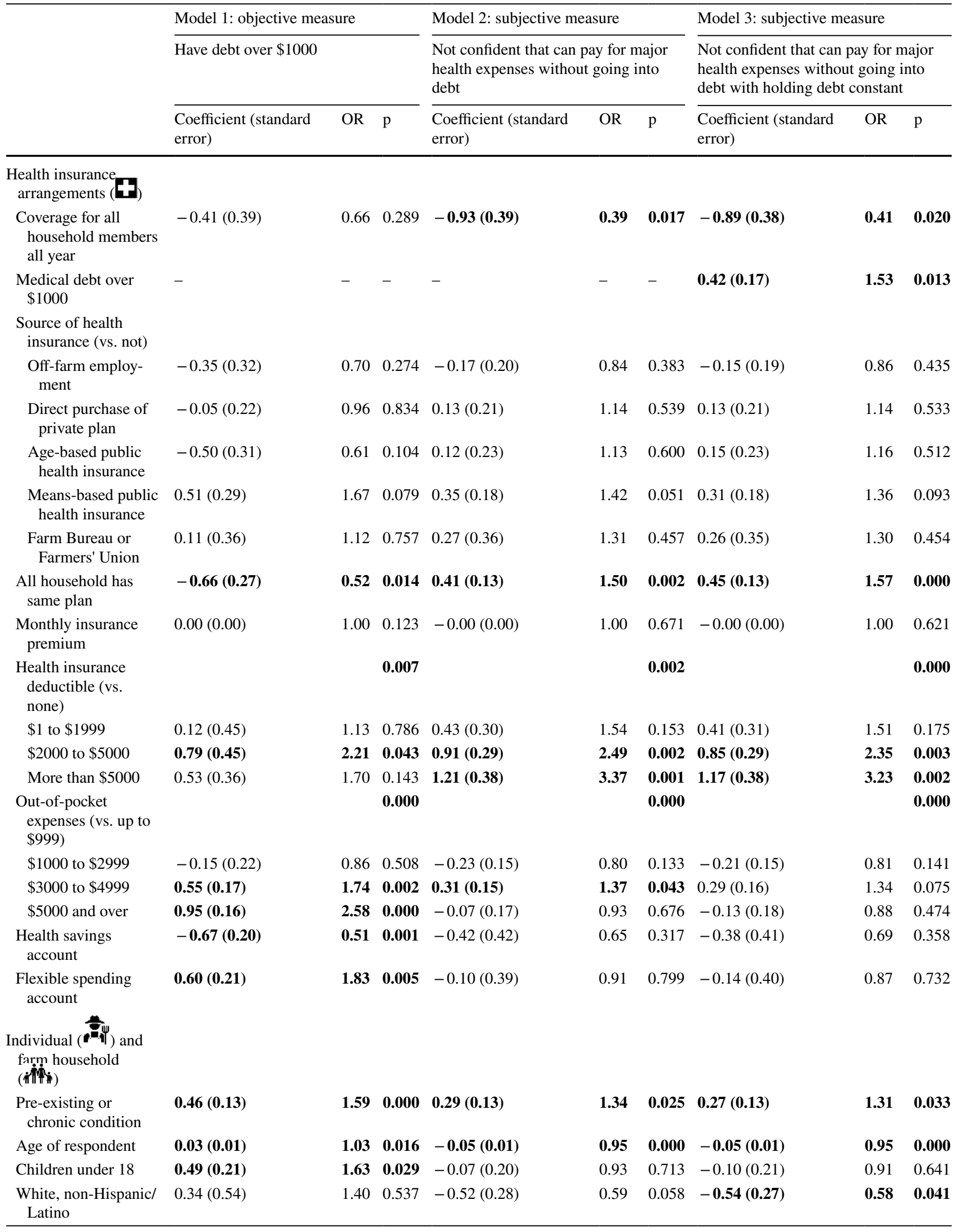


Table 3 (continued)

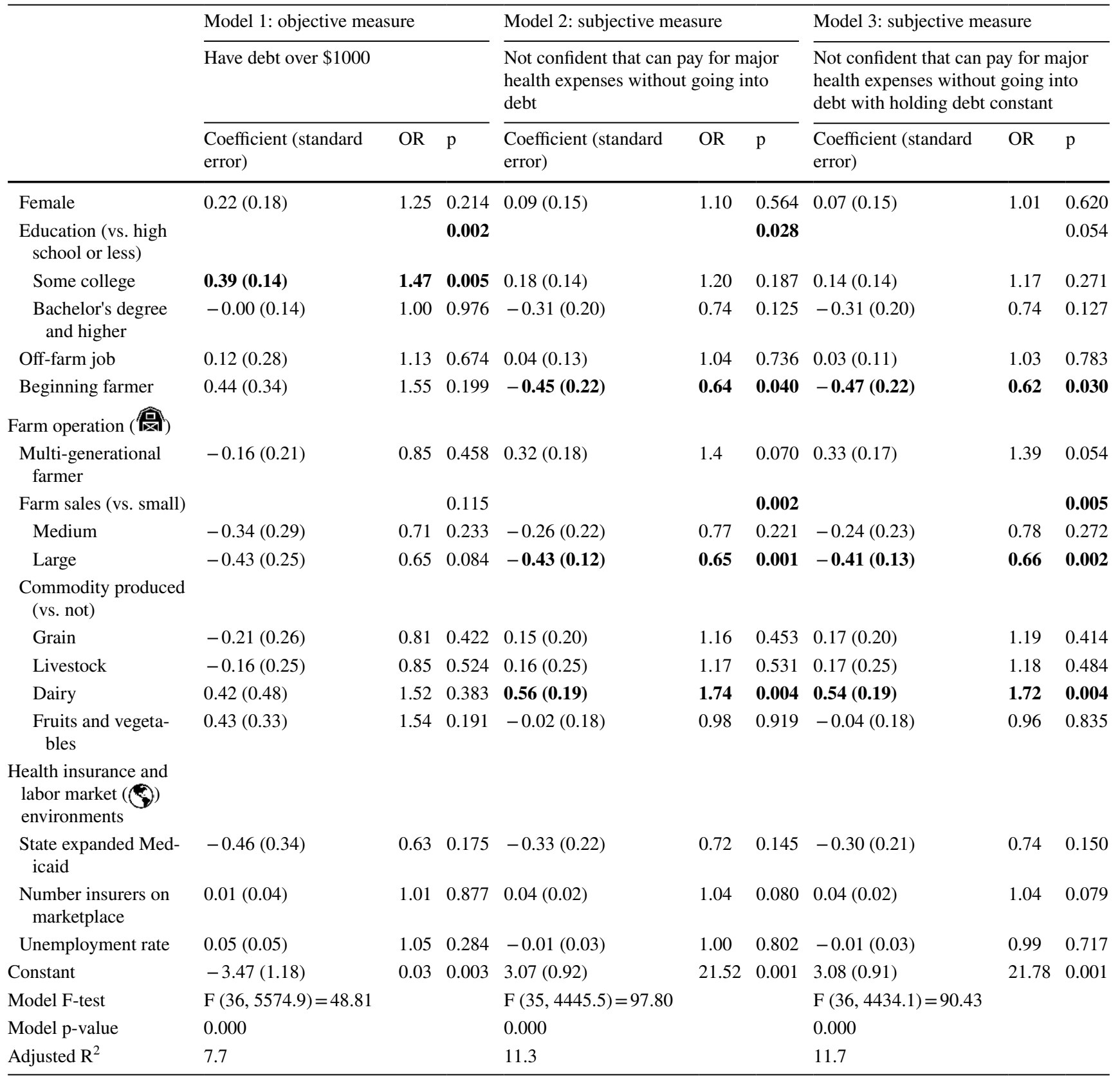

other independent variables, the odds of not being confident in the ability to pay for the cost of a major illness or injury without going into debt are 59\% lower for households with health insurance coverage for all members all year. Conversely, the odds of not being confident in having the ability to pay for a major illness or injury are $53 \%$ higher for households with a medical debt over $\$ 1000,57 \%$ higher for households covered under the same plan, 2.35 times higher for those with deductibles between $\$ 2000$ and $\$ 5000$, and 3.23 times higher for those with deductibles $\$ 5000$ and over compared to households with no deductibles. Turning to farm household demographics, the odds of not being confident in the ability to pay for major health expenses are $31 \%$ higher for households with a pre-existing condition, decrease by $5 \%$ for every increase in age, are $42 \%$ lower for White, non-Hispanic/Latino respondents, and are $38 \%$ lower for beginning farmers. Looking at farm operation variables, the odds of not being confident in the ability to pay are $34 \%$ lower for large-scale farm operations compared to small farms and $72 \%$ higher for dairy operations compared to non-dairy farming operations. Compared to model 1 with the objective outcome measure, variables connected to outof-pocket expenses, having HSA and FSA accounts, having 
children under 18 , and having a college education are no longer statistically significant.

\section{Discussion}

Our three research questions aimed to assess the prevalence and factors associated with medical economic vulnerability among a sample of over 900 U.S. farm families. We now synthesize our results by comparing and contrasting our results with the literature, including the literature that formed the basis of our conceptual framework. We consider the larger implications of our results within the context of the broader farm resilience literature and current limitations in the conclusion.

\section{Prevalence of medical economic vulnerability and variations based on measures used}

Our first research question aimed to assess the prevalence of U.S. farm households experiencing medical vulnerability. We used two measures (one objective, the other subjective) of vulnerability in response to farm resilience scholars' calls to move beyond the current focus on objective measures by analyzing subjective measures that speak to farmers' realities and perceptions (Darnhofer et al. 2016; Meuwissen et al. 2019; Perrin et al. 2020). Our univariate analysis points to important differences in the prevalence of medical economic vulnerability for the two measures. Though only one in five surveyed farm households had a medical debt over $\$ 1000$ in 2016, more than half were not confident that they could pay for a major health expense without going into debt. In other words, the concern of having to take on a debt in anticipation of a major medical problem was 2.7 times higher than having a medical debt over $\$ 1000$. The discrepancy between objective and subjective outcome measures have been found both in the medical economic vulnerability among the general population (Asebedo and Wilmarth 2017; Banegas et al. 2016) and in surveys of farmers pre-ACA (Dulitz and Schrader 2013; Pryor et al. 2008, 2009). The finding of a general sense of medical economic vulnerability based on the subjective measure also connects back to two bodies of literature. First, the health shock literature from low and medium-income countries has found high prevalence of medical vulnerability that are in some cases higher than farm-operation level challenges such as weather events or pest pressure (Alam and Mahal 2014; Bonfrer and Gustafsson-Wright 2017). This body of literature is important since besides a few studies pre-ACA in the U.S., we are not aware of studies on medical economic vulnerability among the agricultural population in high-income countries. Second, the U.S. farm stress literature has found that health-related expenses are a stressor in magnitude similar to farm-related stressors such as cost of land and farm input (Fraser et al. 2005; Inwood 2015; Jackson-Smith et al. 2021).

\section{Limited variations in who experiences medical economic vulnerability}

Our second research question aimed at assessing who is more likely to experience medical economic vulnerability on the basis of farm individual and household demographics as well as farm characteristics (i.e. the role of micro-level spheres within the agri-family system). Despite a somewhat heterogeneous sample of farm families, our multivariate analysis indicates that few variables are statistically significantly associated with the two measures of economic vulnerability with some variations across the objective and subjective measures. In line with previous research (Baughman et al. 2015; Hamel et al. 2016; Katchova and Dinterman 2018; Pryor et al. 2008, 2009; Wiltshire et al. 2016), having a pre-existing or chronic health condition was associated with both outcome measures. In contrast, having children under 18 and lower educational attainment was associated with having a medical debt while White, non-Hispanic respondents, farmers not operating a dairy farm, and operating a large operation (compared to a small operation) were associated with being confident, or neutral, in their ability to pay for major expenses without going into debt. The increase in having a medical debt as respondents age coupled with the decrease in not being concerned in ability to pay for major expenses is similar to the mixed findings around age in previous research (Baughman et al. 2015; Hamel et al. 2016; Himmelstein et al. 2009; Pryor et al. 2008, 2009) and highlights differences based on outcome measures. The difference in the sign of the association may be explained by the increase in health care needs and accumulation of debt over the years while farmers eligible for age-based public insurance have previously reported lower level of challenges paying for health expenses (Dulitz and Schrader 2013; Lottero et al. 2007). Lastly, a greater level of confidence among beginning farmer respondents to pay for medical expenses differs from the farm economic stress literature (Katchova and Dinterman 2018). Our finding may be explained by the lower age of beginning farmer respondents and/or a healthy worker effect (i.e., those self-selecting to enter agriculture are more likely to be healthy). Indeed, one-third of beginning farmer respondents reported a pre-existing or chronic health condition compared to two-thirds of non-beginning farmer respondents.

The overall limited variation in who experiences medical economic vulnerability on the basis of demographic and farm characteristics is a counterpoint to farm resilience assessments that at times place a heavy emphasis on these individual-level variables. Instead, our results align with Chang et al.'s (2011) finding that demographic 
characteristics played a limited role in health-related early exit from agriculture. This finding could in part be reflective of the dangerous and physical nature of agricultural work, which is captured in our dataset (e.g. approximately $60 \%$ of respondents reported at least one household member with a pre-existing or chronic health condition). The limited variation may also be explained by the general sense of medical economic vulnerability found both in our sample and preACA farmer surveys (Dulitz and Schrader 2013; Pryor et al. 2008, 2009). Meanwhile, we note that three of the demographic and farm characteristics that are statistically significant for the subjective measure (i.e. beginning farmer status, farm sales, and dairy production) can be acted on through federal-level agricultural programs in the Farm Bill. Though we did not ask about participation in farm programs, our findings reinforce the importance of assessing systems' features that support farm resilience (Darnhofer 2021) including the need for future research aimed at understanding the role that agricultural policy may play in shaping medical economic vulnerability.

\section{Importance of health insurance arrangements in shaping medical economic vulnerability}

Our third research question aimed to assess the role of institutional arrangements in medical economic vulnerability with a focus on health insurance coverage (i.e. role of macrolevel factors). Our univariate analysis points to the on-going problem of underinsurance (Pryor et al. 2008, 2009). Indeed, despite over 9 in 10 respondents having health insurance coverage for all household members all year, 1 in 5 reported a medical debt and over half are not confident in their ability to pay for major medical expenses. Second, our multivariate analysis hints at the importance of health insurance relative to demographic and farm operation characteristics as seen through a comparison of the size of the statistically significant coefficients. Out of the five largest coefficients for the two outcome measures, four of these coefficients were for health insurance variables. This finding parallels studies examining medical economic vulnerability among the general population (Hamel et al. 2016; Himmelstein et al. 2005).

Our multivariate analysis also indicates that experiencing medical economic vulnerability is not simply a matter of having health insurance coverage but also a matter of the type of coverage a household has with variations based on outcome measures. For example, reporting that all households were covered on the same plan decreased the probability of having a medical debt but increased the probability of not being confident in the ability to pay for major expenses. Another example comes from variables connected to healthrelated expenses. The cost of a health insurance premium was not statistically significant for either outcome variables though the level of financial coverage (i.e., deductibles, out-of-pocket expenses, and HSAs) varied across the two models.

Overall, there are important discrepancies between our findings and previous studies related to the relationships between medical economic vulnerability and health insurance coverage, source of coverage, and health insurance environment (Banegas et al. 2016; Baughman et al. 2015; Frank and McGuire 2017; Mazurenko et al. 2018; Pryor et al. 2009). There are several potential explanations for these discrepancies. First, in pre-ACA studies of farmers, health insurance arrangement variables were limited to health insurance coverage, source, and health expenses. The association between medical debt and health insurance coverage might not be present in our study due to the greater level of granularity in the measures we used. This highlights the importance of including variables that speak to the specifics of health insurance coverage in future studies to fully assess the role of health insurance arrangements. The lack of significance in our study for the macro-level health insurance variables could be in part connected to the small number of study states. It could also be indicative of the relatively limited variations across states in health insurance environments since federal regulations limit the range of variations in terms of what private health insurers and states can offer. The discrepancy may also be explained by variations in outcome variables used across studies, especially for the subjective measure.

\section{Conclusion}

In response to contemporary crises, including climate change, trade liberalization, and more recently the COVID19 pandemic, the farm resilience literature has expanded greatly in recent years with the central objective of understanding farm families' ability to continue farming despite on-going challenges. Yet, two major limitations of this literature, namely, a focus on macro-level challenges faced by the farm operation and a mismatch between the scale of challenges studied (i.e. macro-level) and resilience measures (i.e. largely focused on micro-level variables), likely limit our understanding of the range and frequency of challenges that farm families face and the range of factors that shape resilience. These limitations then call into question our ideas about the types of interventions needed to support the farm sector and farm families' ability to survive a crisis.

In this study, we expand the range of challenges examined in the farm resilience literature by using the example of medical economic vulnerability, a micro-level challenge traditionally confined to the household sphere of the agrifamily system. Our conceptual framework links the medical economic vulnerability and farm economic stress bodies of literature with the multi-scalar agri-family system as 
the backdrop to provide a space to examine the interplay between individual-level factors and features of the bigger system in which farms are embedded. Through an analysis of over 900 surveys of farm households from 10 U.S. states, we found seemingly large differences in the prevalence of medical economic vulnerability across the objective and subjective outcome measures, with the subjective measure indicating a sentiment of medical economic vulnerability among the majority of surveyed respondents. Conversely, there was limited variation in who experiences medical vulnerability based on demographic and farm characteristics while the strongest associations are connected to a households' health insurance arrangements.

Our findings have three main implications for the farm resilience literature. First the presence of medical economic vulnerability among a significant proportion of surveyed farm families (especially for the subjective measure) reinforces recent calls to expand the conceptualization of what constitutes challenges in the resilience literature (Komarek et al. 2020; Popp and Nowack 2020). Our findings point to the importance of including micro-level challenges that impact the farm household. Our study was focused on assessing the prevalence and factors associated with medical economic vulnerability, the next step is to understand how medical economic vulnerability interacts with and affects farm resilience in the medium- and long-term. Understanding farm resilience and building more resilient food and agriculture systems also requires us to grapple with how other micro-level challenges (e.g. a barn fire, loss of off-farm employment, or divorce) impact the farm operation or the household and affect farm resilience.

Second, the variation in results between objective and subjective outcome measures reinforces the importance of using multi-dimensional measurements attentive to both quantitative thresholds deemed indicative of challenges, as well as farmers' lived realities and their perception of current and future prospects (Darnhofer et al. 2016; Meuwissen et al. 2019; Perrin et al. 2020; Rissing 2019). Based on our findings, discounting farm households' lived experience could lead to situations where we overlook the early warning signs of a looming crisis. It could also lead to situation where we ignore low-grade challenges, even if they do not meet the objective measure threshold, that may still erode resilience in the long-term. Inherent in this work is the need to better understand how researchers and practitioners can utilize paired objective and subjective measures to understand current and emerging issues, and the broader types of investments and interventions that contribute to farm resilience at different scales. Since farm resilience studies incorporating subjective measures have largely been qualitative (Daugstad 2019; Perrin et al. 2020), our study provides an example of how objective and subjective measures can be combined in the same quantitative study.

Third, the significant role health insurance arrangements and potential role agricultural policies play in shaping medical economic vulnerability underscore the importance of considering factors beyond the micro-level factors. These findings reinforce critiques of the resilience literature and bolster the need for researchers to account for a broader range of factors that individual farmers do not directly control including meso- and macro-level factors (Calo 2020; Cote and Nightingale 2012; Joseph 2013). Our empirical case is situated in a country with strong farm income support for some sub-agricultural populations compared to some countries (e.g. Australia, Chile, and New Zealand) but with a limited social safety net compared to most other Western industrialized nations. Yet, research from Europe, Canada, and Australia indicates that even with stronger social policies, farm households experience challenges meeting their social and economic needs (Chappuis et al. 2015; Contzen and Crettaz 2019; Contzen et al. 2016; Courtenay Botterill 2007; Droz et al. 2014; Roche 2016). Collectively, these findings reinforce contemporary calls (Becot and Inwood 2020; Darnhofer 2021) to expand the types of issues and variables farm family scholars study. This includes the need to research interactions between institutional arrangements connected to social and agricultural policies and farm resilience.

Acknowledgements We thank Jill Clark, Douglas Jackson-Smith, and Linda Lobao for their comment on a previous version of this article, the HIREDnAg team in particular Bonnie Braun, Stephan Goetz, Jane Kolodinsky, Alana Knudson, Scott Loveridge, Jason Parker, and Robert Parsons for their contributions to survey instrument development, Dan Prager, formally at the U.S. Department of Agriculture, for providing customized ARMS data summary statistics, and Emily Andreae for editorial assistance. We also thank the farm families who took the time to answer the survey.

Funding This study was supported by National Institute of Food and Agriculture, 2015-2014-05623, the Marshfield Clinic Research Institute and, The Ohio State University Initiative for Food and Agricultural Transformation Discovery Theme.

Open Access This article is licensed under a Creative Commons Attribution 4.0 International License, which permits use, sharing, adaptation, distribution and reproduction in any medium or format, as long as you give appropriate credit to the original author(s) and the source, provide a link to the Creative Commons licence, and indicate if changes were made. The images or other third party material in this article are included in the article's Creative Commons licence, unless indicated otherwise in a credit line to the material. If material is not included in the article's Creative Commons licence and your intended use is not permitted by statutory regulation or exceeds the permitted use, you will need to obtain permission directly from the copyright holder. To view a copy of this licence, visit http://creativecommons.org/licenses/by/4.0/. 


\section{References}

Ahearn, M., H. El-Osta, and A. Mishra. 2013. Considerations in work choices of U.S. farm households: The role of health insurance. Journal of Agricultural and Resource Economics 38 (1): 19-33. https://www.jstor.org/stable/23496736. Accessed 11 Feb 2022

Ahearn, M., J. Williamson, and N. Black. 2015. Implications of health care reform for farm businesses and families. Applied Economic Perspectives and Policy 37 (2): 260-286. https://doi. org/10.1093/aepp/ppu030.

Akram-Lodhi, A.H., and C. Kay. 2010a. Surveying the agrarian question (Part 1): Unearthing foundations, exploring diversity. The Journal of Peasant Studies 37 (1): 177-202. https://doi.org/10. 1080/03066150903498838.

Akram-Lodhi, A.H., and C. Kay. 2010b. Surveying the agrarian question (Part 2): Current debates and beyond. The Journal of Peasant Studies 37 (2): 255-284. https://doi.org/10.1080/03066 151003594906

Alam, K., and A. Mahal. 2014. Economic impacts of health shocks on households in low and middle income countries: A review of the literature. Globalization and Health 10 (1): 21. https:// doi.org/10.1186/1744-8603-10-21.

Allison, P. 2012. Handling missing data by maximum likelihood. In SAS global forum, vol. 312. Haverford: Statistical Horizons.

Antonisse, L., R. Garfield, R. Rudowitz, and M. Guth. 2019. The effects of Medicaid expansion under the ACA: Updated findings from a literature review. Menlo Park: Henry Kaiser Family Foundation.

Asebedo, S., and M. Wilmarth. 2017. Does how we feel about financial strain matter for mental health? Journal of Financial Therapy 8 (1): 5. https://doi.org/10.4148/1944-9771.1130.

Banegas, M., G. Guy Jr., J. de Moor, D. Ekwueme, K. Virgo, E. Kent, S. Nutt, Z. Zheng, R. Rechis, and K.R. Yabroff. 2016. For working-age cancer survivors, medical debt and bankruptcy create financial hardships. Health Affairs 35 (1): 54-61. https:// doi.org/10.1377/hlthaff.2015.0830.

Baughman, K., R. Burke, M. Hewit, J. Sudano, J. Meeker, and S. Hull. 2015. Associations between difficulty paying medical bills and forgone medical and prescription drug care. Population Health Management 18 (5): 358-366. https://doi.org/10. 1089/pop.2014.0128.

Becot, F., and S. Inwood. 2020. The case for integrating household social needs and social policy into the international family farm research agenda. Journal of Rural Studies 77: 185-198. https:// doi.org/10.1016/j.jrurstud.2020.05.005.

Bennett, J., and S. Kohl. 1982. Of time and the enterprise: North American family farm management in a context of resource marginality. Minneapolis: University of Minnesota Press.

Bonfrer, I., and E. Gustafsson-Wright. 2017. Health shocks, coping strategies and foregone healthcare among agricultural households in Kenya. Global Public Health 12 (11): 1369-1390. https://doi.org/10.1080/17441692.2015.1130847.

Bryant, H., and A. Maisashvili. 2017. A simple model of farm bankruptcies. AFPC Research Report 17 (2): 1-5.

Burke, A., A. Misra, and S. Sheingold. 2014. Premium affordability, competition, and choice in the health insurance marketplace, 2014. Washington, DC: U.S. Department of Health and Human Services.

Buttel, F. 2001. Some reflections on late twentieth century agrarian political economy. Sociologia Ruralis 41 (2): 165-181. https:// doi.org/10.1111/1467-9523.00176.

Calo, A. 2020. "Who has the power to adapt?" Frameworks for resilient agriculture must contend with the power dynamics of land tenure. Frontiers in Sustainable Food Systems 4: 259. https:// doi.org/10.3389/fsufs.2020.555270.

Carlin, J., J. Galati, and P. Royston. 2008. A new framework for managing and analyzing multiply imputed data in Stata. The Stata Journal 8 (1): 49-67. https://doi.org/10.1177/15368 67X0800800104.

Carolan, M. 2018. Lands changing hands: Experiences of succession and farm (knowledge) acquisition among first-generation, multigenerational, and aspiring farmers. Land Use Policy 79: 179-189. https://doi.org/10.1016/j.landusepol.2018.08.011.

Chang, K.-L., G. Langelett, and A. Waugh. 2011. Health, health insurance, and decision to exit from farming. Journal of Family and Economic Issues 32 (2): 356-372. https://doi.org/10.1007/ s10834-011-9254-3.

Chappuis, M., P. Dessenne, C. Laurenson, O. Lesens, L. Magnin, and G. Norman. 2015. Etat de santé \& accès aux soins des agriculteurs des Combrailles. Paris: Médecins du Monde.

Clark, J., D. Munroe, and B. Mansfield. 2010. What counts as farming: How classification limits regionalization of the food system. Cambridge Journal of Regions, Economy and Society 3 (2): 245-259. https://doi.org/10.1093/cjres/rsq018.

Contzen, S., and E. Crettaz. 2019. Being a poor farmer in a wealthy country: A Swiss case study. Sociologia Ruralis 59 (3): 393-418. https://doi.org/10.1111/soru.12230.

Contzen, S., K. Zbinden, C. Neuenschwander, and M. Métrailler. 2016. Retirement as a discrete life-stage of farming men and women's biography? Sociologia Ruralis 57 (S1): 730-751. https://doi.org/ 10.1111/soru.12154.

Cote, M., and A. Nightingale. 2012. Resilience thinking meets social theory situating social change in socio-ecological systems (SES) research. Progress in Human Geography 36 (4): 475-489. https:// doi.org/10.1177/0309132511425708.

Courtenay Botterill, L. 2007. Responding to farm poverty in Australia. Australian Journal of Political Science 42 (1): 33-46. https://doi. org/10.1080/10361140601158534.

D'Antoni, J., A. Mishra, and S. Chintawar. 2009. Predicting financial stress in young and beginning farmers in the United States. In Paper presented at the Southern Agricultural Economics Association annual meeting, Atlanta, GA.

Darnhofer, I. 2020. Farm resilience in the face of the unexpected: Lessons from the COVID-19 pandemic. Agriculture and Human Values 37: 605-606. https://doi.org/10.1007/s10460-020-10053-5.

Darnhofer, I. 2021. Resilience or how do we enable agricultural systems to ride the waves of unexpected change? Agricultural Systems 187: 102997. https://doi.org/10.1016/j.agsy.2020.102997.

Darnhofer, I., J. Fairweather, and H. Moller. 2010. Assessing a farm's sustainability: Insights from resilience thinking. International Journal of Agricultural Sustainability 8 (3): 186-198. https://doi. org/10.3763/ijas.2010.0480.

Darnhofer, I., C. Lamine, A. Strauss, and M. Navarrete. 2016. The resilience of family farms: Towards a relational approach. Journal of Rural Studies 44: 111-122. https://doi.org/10.1016/j.jrurstud. 2016.01.013.

Daugstad, K. 2019. Resilience in mountain farming in Norway. Sustainability 11 (12): 3476. https://doi.org/10.3390/su11123476.

Dillman, D., J. Smyth, and L.M. Christian. 2014. Internet, phone, mail, and mixed-mode surveys: The tailored design method. Hoboken: Wiley.

Dinterman, R., A.L. Katchova, and J.M. Harris. 2018. Financial stress and farm bankruptcies in U.S. agriculture. Agricultural Finance Review 78 (4): 441-456.

Diserens, F., J.M.H. Choptiany, D. Barjolle, B. Graeub, C. Durand, and J. Six. 2018. Resilience assessment of Swiss farming systems: Piloting the SHARP-Tool in Vaud. Sustainability 10 (12): 4435. https://doi.org/10.3390/su10124435. 
Doeksen, A., and D. Symes. 2015. Business strategies for resilience: The case of Zeeland's oyster industry. Sociologia Ruralis 55 (3): 325-342. https://doi.org/10.1111/soru.12099.

Donham, K., and A. Thelin. 2016. Agricultural medicine: Occupational and environmental health for the health professions, 2nd edn Aufl. Hoboken: Wiley-Blackwell.

Droz, Y., V. Mieville-Ott, D. Jacques-Jouvenot, and G. Lafleur. 2014. Malaise en agriculture. Une approche interdisciplinaire des politiques agricoles France-Québec-Suisse. Paris: Karthala Editions.

Dulitz, M., and S.L. Schrader. 2013. Betting the farm: Health coverage, behaviors and concerns among South Dakota farmers. South Dakota Medicine: The Journal of the South Dakota State Medical Association 66 (10): 405-411.

Field, R. 2017. Regulation of health care in the United States: Complexity, confrontation and compromise. Anais do Instituto de Higiene e Medicina Tropical 16: 61-70.https://doi.org/10.25761/ anaisihmt.45.

Forney, J., and P. Stock. 2014. Conversion of family farms and resilience in Southland, New Zealand. International Journal of Sociology of Agriculture and Food 21 (1): 7-29. https://doi.org/10. 48416/ijsaf.v21i1.152.

Frank, R., and T. McGuire. 2017. Regulated Medicare advantage and marketplace individual health insurance markets rely on insurer competition. Health Affairs 36 (9): 1578-1584. https://doi.org/10. 1377/hlthaff.2017.0613.

Franks, J. 1998. Predicting financial stress in farm businesses. European Review of Agricultural Economics 25 (1): 30-52.

Fraser, C., K. Smith, F. Judd, J. Humphreys, L. Fragar, and A. Henderson. 2005. Farming and mental health problems and mental illness. International Journal of Social Psychiatry 51 (4): 340-349. https://doi.org/10.1177/0020764005060844.

Gillespie, G., and S.E. Johnson. 2010. Success in farm start-ups in the Northeastern United States. Journal of Agriculture, Food Systems, and Community Development 1 (1): 31-48. https://doi.org/ 10.5304/jafscd.2010.011.008.

Greenhill, J., D. King, A. Lane, and C. MacDougall. 2009. Understanding resilience in South Australian farm families. Rural Society 19 (4): 318-325.

Hall, P., and M. Lamont. 2013. Social resilience in the neoliberal era. New York: Cambridge University Press.

Hamel, L., M. Norton, K. Pollitz, L. Levitt, G. Claxton, and M. Brodie. 2016. The burden of medical debt: Results from the Kaiser Family Foundation/New York Times Medical Bills Survey. Menlo Park: Kaiser Family Foundation.

He, Y. 2010. Missing data analysis using multiple imputation: Getting to the heart of the matter. Circulation: Cardiovascular Quality and Outcomes 3 (1): 98-105. https://doi.org/10.1161/CIRCO UTCOMES.109.875658.

Henry Kaiser Family Foundation. 2019. Status of state action on the Medicaid expansion decision. https://www.kff.org/health-reform/ state-indicator/state-activity-around-expanding-medicaid-underthe-affordable-care-act/?currentTimeframe $=0 \&$ sortModel $=\%$ 7B \% 22colId\%22:\%22Location $\% 22, \% 22$ sort $\% 22: \% 22$ asc $\% 22 \%$ 7D. Accessed 5 Jan 2022

Himmelstein, D., E. Warren, D. Thorne, and S. Woolhandler. 2005. Illness and injury as contributors to bankruptcy. Health Affairs 24 (Suppl 1): 63-73. https://doi.org/10.1377/hlthaff.w5.63.

Himmelstein, D., D. Thorne, E. Warren, and S. Woolhandler. 2009. Medical bankruptcy in the United States, 2007: Results of a national study. The American Journal of Medicine 122 (8): 741746. https://doi.org/10.1016/j.amjmed.2009.04.012.

Hox, J. 2010. Multilevel analysis: Techniques and applications, 2nd ed. New York: Routledge.

International Labor Organization. 2014. World Social Protection Report 2014/15: Building Economic Recovery, Inclusive
Development and Social Justice. Geneva: International Labor Organization.

Inwood, S. 2015. Opportunities for extension: Linking health insurance and farm viability. Journal of Extension 53 (3): \#3FEA1. https:// tigerprints.clemson.edu/joe/vol53/iss3/6. Accessed 11 Feb 2022

Inwood, S. 2017. Agriculture, health insurance, human capital and economic development at the rural-urban-interface. Journal of Rural Studies 54: 1-14. https://doi.org/10.1016/j.jrurstud.2017.05.009.

Inwood, S., J. Clark, and M. Bean. 2013. The differing values of multigeneration and first-generation farmers: Their influence on the structure of agriculture at the rural-urban interface. Rural Sociology 78 (3): 346-370. https://doi.org/10.1111/ruso.12012.

Inwood, S., A. Knudson, F. Becot, B. Brown, S. Goetz, J. Kolodinsky, S. Loveridge, et al. 2018. Health insurance and national farm policy. Choices 33 (1): 1-7. https://www.jstor.org/stable/ 26487425. Accessed 11 Feb 2022

Jackson-Smith, D., S. Inwood, A. Rissing, and T. Woods. 2021. Taking the pulse of Ohio farmers: The health status of Ohio farmers. Wooster: The Ohio State University.

Javadinejad, S., R. Dara, and F. Jafary. 2020. Analysis and prioritization the effective factors on increasing farmers resilience under climate change and drought. Agricultural Research 10: 497-513. https://doi.org/10.1007/s40003-020-00516-w.

Joseph, J. 2013. Resilience as embedded neoliberalism: A governmentality approach. Resilience 1 (1): 38-52. https://doi.org/10.1080/ 21693293.2013.765741.

Kangogo, D., D. Dentoni, and J. Bijman. 2020. Determinants of farm resilience to climate change: The role of farmer entrepreneurship and value chain collaborations. Sustainability 12 (3): 868. https:// doi.org/10.3390/su12030868.

Katchova, A., and R. Dinterman. 2018. Evaluating financial stress and performance of beginning farmers during the agricultural downturn. Agricultural Finance Review 78 (4): 457-469. https://doi. org/10.1108/AFR-08-2017-0074.

Komarek, A., A. De Pinto, and V. Smith. 2020. A review of types of risks in agriculture: What we know and what we need to know. Agricultural Systems 178: 102738. https://doi.org/10.1016/j.agsy. 2019.102738

Kuhmonen, I. 2020. The resilience of Finnish farms: Exploring the interplay between agency and structure. Journal of Rural Studies 80: 360-371. https://doi.org/10.1016/j.jrurstud.2020.10.012.

Lottero, B., C. Pryor, M. Rukavina, J. Prottas, and A. Knudson. 2007. Health insurance survey of farm and ranch operators-Overview of findings. Boston: The Access Project.

Mazurenko, O., C. Balio, R. Agarwal, A. Carroll, and N. Menachemi. 2018. The effects of Medicaid expansion under the ACA: A systematic review. Health Affairs 37 (6): 944-950. https://doi.org/10. 1377/hlthaff.2017.1491.

Meuwissen, M., P. Feindt, A. Spiegel, C. Termeer, E. Mathijs, Y. de Mey, R. Finger, A. Balmann, E. Wauters, and J. Urquhart. 2019. A framework to assess the resilience of farming systems. Agricultural Systems 176: 102656. https://doi.org/10.1016/j.agsy.2019. 102656.

Mishra, A., M. Harris, and M. Bampasidou. 2018. Health insurance coverage and labor allocation of beginning farm operator households. In Agricultural and Applied Economics Association annual meeting, Washington, DC.

Mulligan, J., S. Arriaga, and J. Torres. 2019. An ethnographic study of enrollment obstacles in Rhode Island, USA: Struggling to get covered on an Affordable Care Act insurance marketplace. Critical Public Health 29 (5): 547-559. https://doi.org/10.1080/09581 596.2018.1495827.

Nadolnyak, D., V. Hartarska, and B. Griffin. 2019. The impacts of economic, demographic, and weather factors on the exit of beginning farmers in the United States. Sustainability 11 (16): 4280. https:// doi.org/10.3390/su11164280. 
Perrin, A., M. San Cristobal, R. Milestad, and G. Martin. 2020. Identification of resilience factors of organic dairy cattle farms. Agricultural Systems 183: 102875. https://doi.org/10.1016/j.agsy.2020. 102875.

Peters, K., S. Gupta, N. Stoller, and B. Mueller. 2008. Implications of the aging process: Opportunities for prevention in the farming community. Journal of Agromedicine 13 (2): 111-118. https:// doi.org/10.1080/10599240802202497.

Popp, T., and W. Nowack. 2020. Resilience through the financialisation of risks? The case of a dairy system in northwest Germany. Sustainability 12 (15): 6226. https://doi.org/10.3390/su12156226.

Pryor, C., J. Prottas, B. Lottero, M. Rukavina, and A. Knudson. 2008. Who experiences financial hardship because of health care costs. In 2007 Health insurance survey of farm and ranch operators. Boston: The Access Project.

Pryor, C., J. Prottas, B. Lottero, M. Rukavina, and A. Knudson. 2009. Who has medical debts and what are the consequences? In 2007 Health insurance survey of farm and ranch operators. Boston: The Access Project.

Reed, D. 2008. America's aging farmers: Tenacious, productive, and underresearched. Journal of Agromedicine 13 (2): 69-70. https:// doi.org/10.1080/10599240802293942.

Reinhardt, N., and P. Barlett. 1989. The persistence of family farms in United States agriculture. Sociologia Ruralis 29 (3-4): 203-225. https://doi.org/10.1111/j.1467-9523.1989.tb00367.x.

Rice, T., P. Rosenau, L. Unruh, A. Barnes, R. Saltman, and E. van Ginneken. 2013. United States of America: Health system review. Health Systems in Transition 15 (3):1-431. https://apps.who.int/ iris/handle/10665/330305. Accessed 11 Feb 2022

Richardson, T., P. Elliott, and R. Roberts. 2013. The relationship between personal unsecured debt and mental and physical health: A systematic review and meta-analysis. Clinical Psychology Review 33 (8): 1148-1162. https://doi.org/10.1016/j.cpr.2013. 08.009 .

Rissing, A. 2019. "Profitability" vs. "Making It:" Causes and consequences of disembedding beginning farms' finances. Culture, Agriculture, Food and Environment 41 (2): 149-157. https://doi. org/10.1111/cuag. 12234 .

Robert Wood Johnson Foundation. n.d. HIX Compare datasets 2014 to 2019. https://hixcompare.org/. Accessed 15 Jan 2019.

Roche, A. 2016. Des vies de pauvres: les classes populaires dans le monde rural. Collection "Essais". Rennes: Presse Universitaire de Rennes.

Royston, P., and I. White. 2011. Multiple imputation by chained equations (MICE): Implementation in Stata. Journal of Statistical Software 45 (4): 1-20.

Shepard, L.E., and R.A. Collins. 1982. Why do farmers fail? Farm bankruptcies 1910-78. American Journal of Agricultural Economics 64 (4): 609-615. https://doi.org/10.2307/1240569.

Shortall, S., A. McKee, and L.A. Sutherland. 2019. Why do farm accidents persist? Normalising danger on the farm within the farm family. Sociology of Health and Illness 41 (3): 470-483. https:// doi.org/10.1111/1467-9566.12824.

Sinclair, K., A. Curtis, E. Mendham, and M. Mitchell. 2014. Can resilience thinking provide useful insights for those examining efforts to transform contemporary agriculture? Agriculture and Human Values 31 (3): 371-384. https://doi.org/10.1007/ s10460-014-9488-4.

Smithers, J., and P. Johnson. 2004. The dynamics of family farming in North Huron County, Ontario. Part I. Development trajectories.
The Canadian Geographer 48 (2): 191-208. https://doi.org/10. 1111/j.0008-3658.2004.00055.x.

Sweet, E., A. Nandi, E. Adam, and T. McDade. 2013. The high price of debt: Household financial debt and its impact on mental and physical health. Social Science and Medicine 91: 94-100. https:// doi.org/10.1016/j.socscimed.2013.05.009.

Thorsøe, M., E. Noe, D. Maye, M. Vigani, J. Kirwan, H. Chiswell, M. Grivins, A. Adamsone-Fiskovica, T. Tisenkopfs, and E. Tsakalou. 2020. Responding to change: Farming system resilience in a liberalized and volatile European dairy market. Land Use Policy 99: 105029. https://doi.org/10.1016/j.landusepol.2020.105029.

UCLA. n.d. Institute for Digital Research and Education: Multiple imputation in STATA. https://stats.idre.ucla.edu/stata/seminars/ mi_in_stata_pt1_new/. Accessed 2 Nov 2019.

Urruty, N., D. Tailliez-Lefebvre, and C. Huyghe. 2016. Stability, robustness, vulnerability and resilience of agricultural systems. A review. Agronomy for Sustainable Development 36: 1-15. https:// doi.org/10.1007/s13593-015-0347-5.

USBLS. 2016. Local area unemployment statistics. https://www.bls. gov/lau/. Accessed 1 Feb 2022.

U.S. Department of Agriculture. 2017. Census of agriculture. Washington, DC: U.S. Department of Agriculture.

USDA. 2021. USDA to invest more than \$4 billion to strengthen food system. https://www.usda.gov/media/press-releases/2021/06/08/ usda-invest-more-4-billion-strengthen-food-system. Accessed 13 Aug 2021.

van Ginkel, J., M. Linting, R. Rippe, and A. van der Voort. 2020. Rebutting existing misconceptions about multiple imputation as a method for handling missing data. Journal of Personality Assessment 102 (3): 297-308. https://doi.org/10.1080/00223891.2018. 1530680.

White, I., P. Royston, and A. Wood. 2011. Multiple imputation using chained equations: Issues and guidance for practice. Statistics in Medicine 30 (4): 377-399. https://doi.org/10.1002/sim.4067.

Wiltshire, J., K. Elder, C. Kiefe, and J. Allison. 2016. Medical debt and related financial consequences among older African American and white adults. American Journal of Public Health 106 (6): 1086-1091. https://doi.org/10.2105/AJPH.2016.303137.

World Bank. n.d. What we do. https://www.worldbank.org/en/what-wedo. Accessed 13 Aug 2021.

Publisher's Note Springer Nature remains neutral with regard to jurisdictional claims in published maps and institutional affiliations.

Florence A. Becot PhD, is an Associate Research Scientist at the National Farm Medicine Center, a research center embedded in a rural health care system in Wisconsin. A rural sociologist with a background in applied economics and community development, her scholarship is at the intersection of farm households' social and economic needs, social policy, and farm persistence/resilience.

Shoshanah M. Inwood PhD, is an Associate Professor in the School of Environment and Natural Resources at The Ohio State University. A Rural Sociologist, Dr. Inwood's integrated research and extension program focuses on social factors affecting farm viability, health and well-being in the food and agriculture sector, and community and economic development through food and agriculture. 